\title{
AC 2007-1052: LET BLACKBOARD TRACKING EASE THE PAIN OF ASSESSING OUTCOME I
}

\author{
Cindy Waters, North Carolina A\&T State University
}




\begin{abstract}
:
Most engineering programs are secure in their assessment means for the technical skills described in ABET Criterion 3a-k. However, not so clear, is the answer to defining, teaching and assessing the professional outcomes (teamwork, professional and ethical responsibility, communication, impact of engineering solutions, life-long learning, and contemporary issues). The outcome pertaining to life-long learning raises many questions including; what constitutes life-long learning; how will we demonstrate that our graduates recognize the need for and have the ability to lifelong learn; and last but not least, how will we measure this attribute in our graduates? Literature on lifelong learning provides more than the definition, but concrete assessment instruments are not readily available ${ }^{1}$. This poses a challenge because the engineering community strives to implement quantifiable instruments to assess the outcomes. Some researchers makes the statement that the "motivated person is a lifelong learner, and the lifelong learner is a motivated person" ${ }^{2}$. The question to ask is, how can we measure motivation? The newest widely accepted learning theory, constructivism, represents a paradigm in which learners construct knowledge for themselves. The basic premise is that an individual learner must actively "build" knowledge and skills ${ }^{3}$. What is more active than having to sign on to the class website, and take the time to link the various extra resources the professor has provided? This paper will describe a work in progress to use Blackboard's tracking tool to assess this active construction of knowledge which can be linked to the "Recognition of need for and ability to engage in life-long learning". At the initial stage our plan does not create a validated predictive instrument, but tries to compare the grades of students who utilize the resources available on a very interactive Blackboard course website to those who do not and infer that this will contribute to choices to engage in lifelong learning.
\end{abstract}

\title{
Introduction:
}

Criteria 3 of ABET 2000 includes professional skills one of which is the propensity for lifelong learning. Research and studies on lifelong learning provides many varied opinions, but concrete assessment instruments are not readily available ${ }^{1}$. This poses a challenge because the engineering community strives to implement quantifiable instruments to assess the outcomes. Some researchers makes the statement that the "motivated person is a lifelong learner, and the lifelong learner is a motivated person" 2 . Once again, how can we measure motivation? The newest widely accepted learning theory, constructivism, represents a paradigm in which learners construct knowledge for themselves and this forms the base for thinking about Lifelong learning. The basic premise is that an individual learner must actively "build" knowledge and skills ${ }^{3}$. We know that technology changes with time and an engineer must be motivated to continue to learn and stay current with technology. Constructivism is a method of teaching and learning based on the principle that cognition (learning) is the result of mental construction, and this construction in quite individual. Knowledge is formed by reflecting on our experiences, by putting information together with what we already thereby we construct knowledge in our head. Thus, we create our own understanding of the world we live in. Learning is the process of adjusting our mental models to fit with new experiences. Constructivist theorists maintain that people learn best when they actively construct their own understanding. This is what we hope our graduates will be able to accomplish. 
In the Constructivist theory the emphasis is placed on the learner rather than the teacher. This is quite pertinent to an engineering graduate out on the job where a formal teacher is not present. It is the learner who interacts with objects and events and thereby gains an understanding of the features held by such objects or events. A course website should therefore contain many different "objects" from which the students can construct their knowledge. The learners individually discover and transform complex information constructing their own conceptualizations and solutions to problems.

Educators also know that students advance through stages of increasing self-direction and intellectual development. In the 1960s and 70s William Perry developed a model for intellectual development among college students. Students progress through three major stages which can be broken further into nine steps. The Perry intellectual development model is quite relevant to lifelong learning and is shown below ${ }^{4}$. Gerald O. Grow in his article from Florida A\&M proposed that learners advance and that teachers can help or hinder that development ${ }^{5}$. When teaching sophomores and higher we hope that they are beyond dualism and well into multiplistic thought. Graduates will likely have progressed even further down the scale and will be in the stage of Relativism where they can "argue their perspective and consider the relative merit of alternative arguments by evaluating the quality of the evidence".

Dualism. (Either/or thinking). Students in this stage believe there is a single right answer to all questions. Knowledge is perceived truth delivered by professors. Basic Duality: All problems are solvable; therefore, the student's task is to learn the Right Solutions. Full Dualism: Some Authorities (literature, philosophy) disagree; others (science, math) agree, therefore, there are Right Solutions, but some teachers' views are obscured. Therefore, student's task is to learn the Right Solutions and ignore the others! They are especially uneasy when teachers (authorities) disagree. They believe that learning involves taking notes, memorizing facts, and later depositing facts on exams.

Multiplicity (subjective knowledge). Early Multiplicity: There are 2 kinds of problems: 1)those whose solutions we know 2)those whose solutions we don't know yet. Student's task is to learn how to find the Right Solutions Late Multiplicity: Most problems are of the second kind; therefore, everyone has a right to their own opinion; or some problems are unsolvable; therefore, it doesn't matter which (if any) solution you choose. Student's task is to shoot the bull. (Most freshmen are at this position, which is a kind of relativism) Students in this stage believe that knowledge is just an opinion, and students and faculty are equally entitled to believe in the veracity of their own opinions. They may rebel at faculty criticism of their work, attributing it to capricious whim and faculty inability to recognize the value in alternative perspectives.

Relativism (constructed knowledge). Students at this level recognize that opinions are based on values, experiences, and knowledge. They can argue their perspective and consider the relative merit of alternative arguments by evaluating the quality of the evidence. Knowledge is constructed through experience and reflection. These students view faculty as having better-informed opinions in their areas of expertise and as being able to teach students techniques for evaluating the quality of evidence underlying conclusions. ${ }^{4}$ 
The self-efficacy or Perceived self-efficacy is another framework or operative construct that has relevance to Lifelong learning studies. A student's self efficacy is related to subsequent behavior and that is ultimately the intent of ABET's inclusion of Life-long learning as a outcome $^{6}$. We should strive to create Engineering graduates who have adequate self-efficacy and therefore the motivation to never stop learning. The construct of Perceived Self-Efficacy reflects a belief that one can execute assigned tasks, or cope with difficulty in a range work and personal settings. A student's perceived self-efficacy aids goal-setting and persistence in face of obstacles and is therefore quite germane to their lifelong learning. When students are encouraged to use all of the available resources to aid in their learning, we hope to develop graduates with the tendency towards the lifelong learning outcome. How can we monitor this progress? We as instructors must practice what we preach and use all of our resources one of which is the web program Blackboard. Many instructors are unaware of the capabilities of the program but the "tracking" capability is quite useful for this application.

During a 3 week period when the tracking was turned on for the external links data was recorded for each item. The assumption is that the student's motivation can be related to the frequency of times they access supplemental information that is made available to them on the class Blackboard cite. The items on Blackboard could be word documents or external links. Figure 1 displays the method used to activate the tracking of student access to the resources. This is taken from the page of Blackboard arrived to via the control panel and then choosing "Options" during the initial set-up or via "Modify" if the item was previously set-up before tracking was chosen.

Figure 1. Display screen from Blackboard where tracking is selected.

\section{Options}

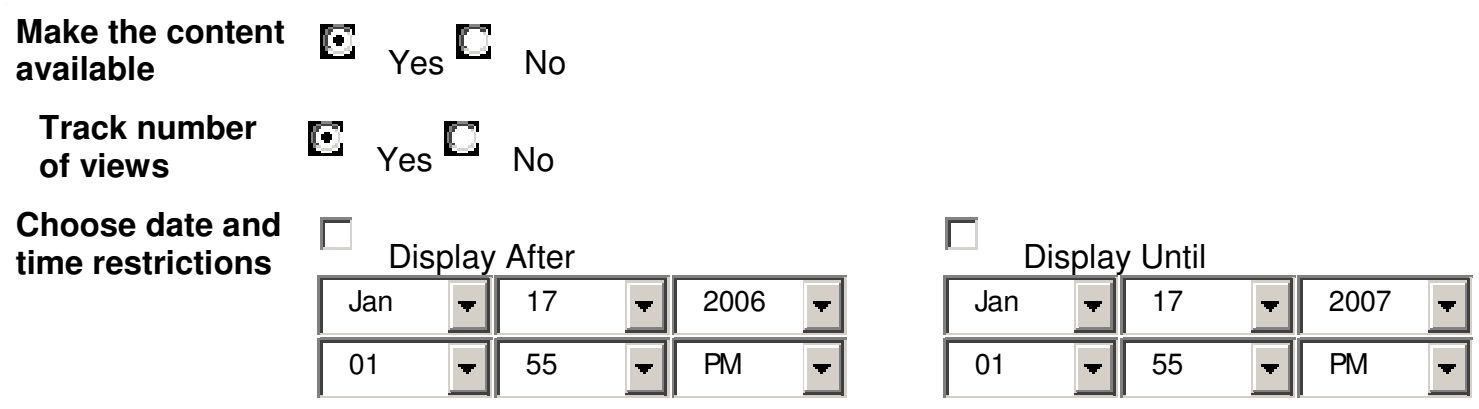

The following data presented is a synopsis of the information that Blackboard provides to the instructor when the tracking is turned on. Blackboard records the following:

1. Access / Date - recorded for each student

2. Access / Day of Week - expressed as a \%, totaled for the entire class

3. Access / Hour of Day - expressed as a \% totaled for the entire class 
A sample of the data is displayed:

Table 1. Synopsis of the data taken from the tracking tool of Blackboard. This is the Access / Date - recorded for each student, i.e. the total number of visits of the tracking period that were selected by the instructor.

\begin{tabular}{|c|c|c|c|}
\hline (a) & $\begin{array}{c}\text { Chapter } 9 \\
\text { Supplemental Notes }\end{array}$ & $\begin{array}{l}\text { Phase Diagram } \\
\text { Supplemental Notes }\end{array}$ & $\begin{array}{c}\text { Final grade of } \\
\text { student }\end{array}$ \\
\hline Student & Total \# visits & Total \# visits & \\
\hline A & 18 & 8 & A \\
\hline B & 2 & 0 & C \\
\hline D & 0 & 0 & $\mathrm{~F}$ \\
\hline E & 2 & 2 & A \\
\hline $\mathrm{F}$ & 0 & 0 & B \\
\hline$G$ & 1 & 1 & C \\
\hline $\mathrm{H}$ & 0 & 0 & B \\
\hline$J$ & 3 & 1 & A \\
\hline K & 0 & 2 & D \\
\hline L & 7 & 4 & B \\
\hline M & 5 & 5 & C \\
\hline $\mathrm{N}$ & 1 & 1 & D \\
\hline O & 1 & 1 & B \\
\hline$P$ & 8 & 5 & C \\
\hline $\mathrm{T}$ & 3 & 3 & B \\
\hline$u$ & 0 & 1 & A \\
\hline v & 0 & 0 & $\mathrm{~F}$ \\
\hline$x$ & 8 & 8 & B \\
\hline z & 0 & 0 & B \\
\hline AA & 3 & 2 & C \\
\hline BB & 0 & 0 & $\mathrm{~F}$ \\
\hline $\mathrm{CC}$ & 2 & 1 & B \\
\hline DD & 1 & 1 & B \\
\hline $\mathrm{EE}$ & 1 & 1 & C \\
\hline $\mathrm{GG}$ & 0 & 0 & B \\
\hline $\mathrm{JJ}$ & 0 & 0 & C \\
\hline KK & 0 & 0 & $\mathrm{~F}$ \\
\hline LL & 6 & 6 & B \\
\hline MM & 1 & 1 & C \\
\hline $\mathrm{NN}$ & 2 & 0 & D \\
\hline PP & 0 & 0 & B \\
\hline $\mathrm{QQ}$ & 4 & 2 & C \\
\hline $\mathrm{RR}$ & 0 & 0 & C \\
\hline SS & 4 & 3 & C \\
\hline TT & 2 & 2 & A \\
\hline UU & 0 & 0 & D \\
\hline TOTAL & 85 & 61 & \\
\hline
\end{tabular}

Analysis of the data from Table 1 show that the students failing the class with an "F" never accessed the supplemental information and of the four students making a " $\mathrm{D}$ " only they together accessed the information only six times. While there are also "A" and "B" students who choose 
not to use the extra resources, generally the highly motivated student's performance was improved by the efforts to gain the additional information. Plans are in place to continue this tracking process and link this to performance on a "motivation" survey each student will take. The student's comments demonstrate that they recognize the importance of their own personal efforts. Additionally, Figure 3 displays the likert scale survey question demonstrating that the students recognize that the "External Links Helped my Learning", $11 \%$ strongly agree, and $\sim 65 \%$ agree and the survey answer to the question "I can say that the resources available on Blackboard have expanded my understanding of Material Science" showed 18\% strongly agree, and $\sim 48 \%$ agree.

\section{Question 2 Essay}

What are things you like about the class?

$>$ There are a lot of things that I like about this class. For one, my teacher brings models and food in to show examples of what we are working on regularly. Also, the teacher gives a lot of examples and notes in class that make it easier for students to understand. Last, but not least, the thing that I really like about the class is that it focuses on everything that I did this summer at an intership. I worked in the Materials Science \& Applications Department and a lot of the things that I did there come up in class very often.

$>$ Dr Waters doesn't lecture, but teach with easy to understand examples. Complex ideas displayed in everyday things we can relate to.

$>$ The thing I like most about the course is that there are so many outside resources that the professor gives us to understand the material. She also has a lot of office hours, and the TA is very helpful.

$>$ l like how the instructor is so energetic and enthusiastic in class. The new WileyPlus assigments that we have are pretty neat, definitely since we get a link to the references in the textbook. I like how the topics in this course relate to chemistry as well as the mechanical engineering side of the world of engineering in general. I am a hands-on learner, and since our instructor puts a lot of extra information on the Blackboard, as well as pass around a lot of 3D materials for us to look at, it has helped me to better understand the topics in the course.

\section{Question 5 Essay}

What is one thing you'd say to your fellow students that would improve the class?

$>$ One thing i'd say to my fellow students that would improve the class is to read the material before class, and come prepared to review what they've read.

>read the book, go to Blackbaord and dont miss class.. and take good notes

$>$ One thing I would say to my fellow students that would improve the class is to be better prepared for class; read and take notes ahead of time. This way our teacher can move faster through the material and possible have more time to demonstrate other topics using 3D models because, as a whole, the class would have less questions and be more focused.

$>$ Read the chapter and definitely if you can't do that check out external links! 
Figure 3. Likert Opinion survey results taken Fall 2006 in the Materials Science class.

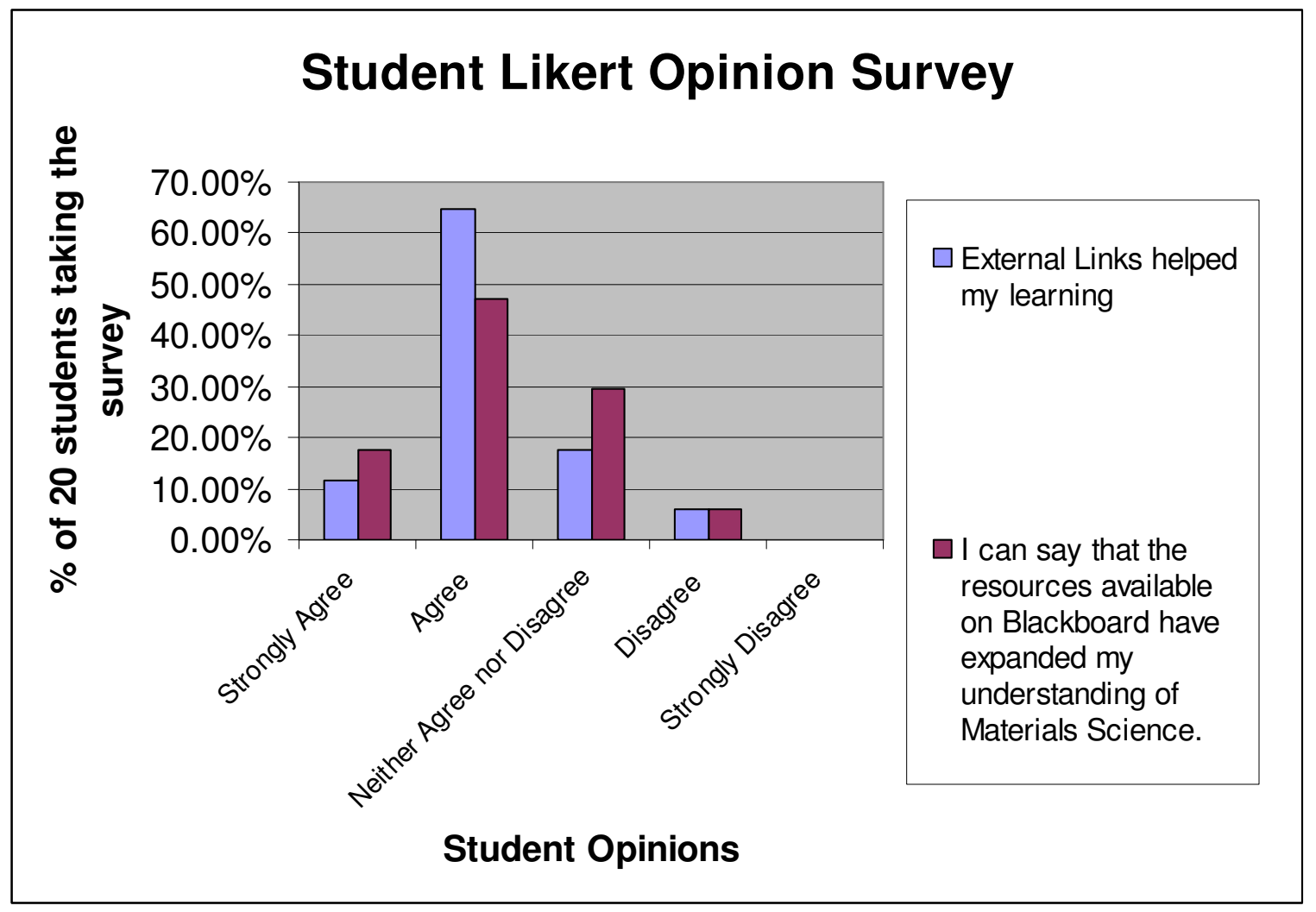

\section{Conclusion:}

The results from the tracking tool in comparison with the grades shows a link to performance but more importantly the qualitative student opinion results show that the students believe that the extra efforts will help. This improves their self-efficacy and reinforces to them that if they are motivated they can improve their learning and grades. The utilization of the resources available on the interactive Blackboard course does seem to strengthen the student's awareness that they have the choice to engage in lifelong learning. This effort is a work in progress and the future plan is to create survey instruments with greater statistical validity and to track more data. The life-long learning outcome is by nature difficult to quantify but the author's understanding of ABET's goals by choosing these particular a-k outcomes, is to increase the exposure of engineering graduates to these areas. At the initial stage this effort is encouraging and work will continue to create a validated predictive instrument, but even at this initial stage positive trends are displayed.

\section{Bibliography}

1. R.. Marra, K. Camplese, T. Litzinger, "Lifelong Learning: A Preliminary Look at the Literature in View of EC 2000”, Proceedings 29th ASEE/IEEE Frontiers in Education Conference, Puerto Rico, Nov. 1999. 
2. B. L. McCombs, “Motivation and lifelong learning," Educational Psychologist, vol. 26, pp. 117-127, 1991.

3. Bruner, J.S. Acts of Meaning. Cambridge, MA: Harvard University Press, 1990.

4. Perry, William G., Jr., Forms of Intellectual and Ethical Development in the College Years: A Scheme (New York: Holt, Rinehart, and Winston) 1970.

5. G. Grow, "Teaching Learners to be Self-Directed", ADULT EDUCATION QUARTERLY, Volume 41, Number 3, Spring, 1991.

6. R. Schwarzer, (Ed.) Self-efficacy: Thought control of action. Washington, DC: Hemisphere, 1992. 